\title{
Supporting student transition to higher education feedback: an evaluation of an online feedback training approach
}

\section{Michael Hast}

St Mary's University, Twickenham, UK

\section{Abstract}

Recent research has indicated higher education students from the current net generation increasingly prefer to access their assignment feedback online rather than in hard copy, allowing universities to harness technological approaches towards a more up-to-date student experience. However, this prior research has also highlighted lack of training for students on how to access and make use of online feedback. The present study therefore evaluates a novel training approach embedded within an undergraduate teaching programme. Students completed a survey on the training approach. A sub-set and an additional comparison group took part in focus groups. The findings indicate a clear need for such specific training, that it can reduce depersonalisation in an age where universities are becoming increasingly digital, and that the transition into higher education can be supported through appropriate realignment of student instruction. More research is required to address the extent of the training's impact on feedback engagement, but the outcomes should contribute to a refining of current approaches to introducing undergraduate students to working with feedback, which should ultimately enhance the overall higher education student experience.

Keywords: online feedback provision; student transition; structured training.

\section{Introduction}

Alongside the rapid developments in technology and an increasingly digitally resourced world (Abrahams, 2010; Altbach et al., 2009; Sarkar, 2012), higher education institutions across the globe are welcoming and engaging with a continually changing student body. The majority of young people entering university today are of the so-called net generation 
(Manuguerra and Petocz, 2011; Prensky, 2012) who are seen as highly comfortable with technology and who, as a result, are looking for learning that reflects this experience (Bradwell, 2009; Lai, 2011). Consequentially, this means that teaching and learning approaches in higher education are increasingly embracing - or having to embrace technology (Laurillard, 2006; Turney et al., 2009; Selwyn, 2016; Walker et al., 2012).

A key area of the higher education experience where students need to be supported is their engagement with assessments. Assessment and feedback engagement are integral to student achievement of educational goals and motivation (Brown et al., 2009; Grieve et al., 2016; Heinrich et al., 2012) and they can promote self-regulated learning (Brown et al., 2016). These issues emphasise the importance of this domain. In particular, assessment and feedback in higher education, too, have gone digital and various studies have examined how technology can be used to support student engagement (e.g. Ambler et al., 2014; Hepplestone et al., 2011; Pellegrino and Quellmalz, 2010; Säljö, 2010). However, despite students increasingly coming from a digitally confident population, their engagement with feedback through digital means is often subject to unexpected difficulties with the particular digital approaches used in higher education settings. This warrants further examination.

Digital approaches to teaching and learning are often seen in a positive light. For instance, many higher education institutions follow blended learning systems that incorporate digital approaches because students make outcome gains (López-Pérez et al., 2013) and they tend to show positive attitudes towards these approaches (López-Pérez et al., 2011). In the particular context of assessment and feedback, digital approaches are viewed favourably by institutions because they help reduce plagiarism (Baker et al., 2008; Batane, 2010) and allow for faster marking, reducing the administrative workload (Buckley and Cowap, 2013). In addition, online marking is seen to be just as valid as marking in hard copy (Shaw, 2008) and feedback is perceived to be more targeted and more effective (Ambler et al., 2014).

Among students, too, preferences are turning more towards online marking and feedback provision. For instance, Hast and Healy (2016) recently found that $86 \%$ of undergraduate students preferred submitting assignments online rather than in hard copy, adding to a growing trend that started with only one in four students showing such a preference just a decade earlier (Ambler et al., 2014; Bridge and Appleyard, 2005; 2008). Similarly, when it 
came to accessing feedback online, Hast and Healy (2016) noted an increase in preferences from prior studies (Ambler et al., 2014; Bridge and Appleyard, 2008), and added by noting similar student preferences for reading feedback online. Added to this are various benefits that students see in digital approaches. In particular, they offer greater flexibility in terms of time and space (Brown et al., 2016; Hast and Healy, 2016; Timmis, Broadfoot et al., 2016; Turney et al., 2009) and increased ease of access (Grieve et al., 2016; Hast and Healy, 2016). In essence, all these allow students to 'work, learn, and study whenever and wherever they want to' (Gosper et al., 2013, p.278).

The changes noted above are most likely a response to the increase in so-called net generation students (Manuguerra and Petocz, 2011; Prensky, 2012) as well as reflecting technological innovations. However, technology is not always categorically seen as a positive in higher education (see e.g. Selwyn, 2016) and it is therefore of essence that any new digital approaches are evaluated as carefully as possible. In doing so, higher education teaching and learning can be realigned and reformed as appropriately as possible. For instance, despite the fact - or assumption made - that many young people now entering higher education are familiar with new technologies, these experiences vary and often do not match the new skills required at university. This means institutions have a responsibility to promote appropriate learning opportunities for students to fully engage with digital approaches (Newman and Scurry, 2015), thereby having to support the transition process in a field that is easily overlooked.

The consequences of a lack of such transition support can be seen in the negative student experiences surrounding online assignments. A key issue for students is that online feedback, in the absence of face-to-face discussion, leads to difficulties in interpretation and use of feedback (Andrade, 2010; Hattie and Timperley, 2007). This lack of relationship with the online marker can have knock-on effects, leading towards depersonalisation and reduced self-regulated learning (McCabe et al., 2011; Parkin et al., 2012) and can, in turn, impede the issue of interpretation. Appropriate engagement on the student behalf contributes to issues such as retention rates, indicating an enhanced engagement with supporting transition (Gale and Parker, 2014; Kift et al., 2010). The issues noted above could be resolved in a relatively simple manner - through the provision of structured training that guides students through all relevant processes, including aspects of submission and access, and clarifying the relationship between online feedback access 
and communicating with tutors to discuss the feedback. Doing so should enhance engagement motivation.

To support students in their transition into online feedback provision, a series of activities was embedded in a first year undergraduate module on learning skills, centring on submission and access. In the first lecture students were given a live demonstration on how to submit work online (Step 1). Importantly, the instructors showed this from the student perspective by having the instructors enrolled on a practice module as a student. This was necessary since the student view of Turnitin is different from that of an instructor. Students were then set a simple writing activity and were asked to submit this assignment online after the lecture (Step 2). The instructors provided basic written feedback on the assignment through Grademark and students were requested to access the feedback online, using video materials posted on the VLE (Virtual Learning Environment) to support the process if this was necessary (Step 3). Following a later assignment on which students were provided with more extensive formative feedback, students were given a lecture on how to use the feedback, including knowing who to speak to and how this could be identified from the feedback (Step 4). What follows in this paper is an evaluation of this structured training approach, drawing on quantitative and qualitative data of student views. Specifically, it seeks to draw on how these views compare to those of students who had not undergone this training.

\section{Method}

The target participants for the present study were undergraduate students in their first year of a social science degree programme at a university in the Greater London area. The research was carried out during the second semester, which meant all of the participants had previous experience of submitting work and accessing feedback online as required by the programme. To gain more detailed insight into the student views a mixed method approach was chosen, combining both statistical trends and personal experiences (Creswell, 2015). Once ethical approval to conduct the research was granted by the host institution's ethics committee, a survey drawing on both quantitative and qualitative data was carried out first, followed by qualitative focus groups. 


\section{Survey}

To gather initial insight the survey covered a range of items and response approaches across two sections using 4-point Likert scales. In the first section, questions were asked around the first writing activity and subsequent feedback access (Steps 1, 2 and 3). In the second section, questions were asked around post-feedback engagement (Step 4). This was then followed by open-ended response opportunities. Questions were asked about perceived ease, perceived usefulness of the training, confidence in relation to future work, and the impact of the training on the students' transition experience.

The survey was distributed to students in hard copy during lectures. Before completion of the survey its purpose was explained to the participants, including how data would be used and stored. The students were then asked to sign a consent form acknowledging their participation. Participants responded anonymously; the survey took approximately 10 minutes to complete. A total of 62 students (55 female) originally registered for the module in question completed the survey. This represents a response rate of $82 \%$. The majority of respondents (81\%) were aged 18 to 20 years at time of degree enrolment, with the remainder identifying as aged 21 or above at that time (classified as mature students; cf. UCAS, 2017).

Following data collection, an initial reliability analysis was carried out on the Likert items in the survey. Cronbach's alpha showed the items to have high internal consistency (10 items; $\alpha=0.83$ ), suggesting the survey to be highly reliable (Cronbach, 1951). All Likert items were found to be worthy of retention for further survey analysis, since removal of any of the items would have reduced the alpha. To then examine any significant relationships amongst the Likert items, Kendall's tau correlations were run. All quantitative data were analysed using SPSS.

\section{Focus groups}

Out of the 62 students who completed the survey, 8 participants were invited to take part in one of two focus groups (Groups 1 and 2), with 4 participants in each. Selection was made to represent the student body as closely as possible in terms of gender (6 female) and age group (7 aged 18-20 at start of course). While recommended focus group sizes are typically five or six participants (cf. Krueger and Casey, 2014), the requirement of specific participants meant that organising appropriate times to conduct a single group 
presented a challenge. A further focus group (Group 3) was run with 4 students who were from the same programme but who had not taken the particular module. Data are presented according to focus group and participant number in that group (e.g. the first participant from the first focus group is referred to as 1.1). All sessions were video recorded to ease the process of transcription. Prior to the recording students were given information about the purpose of the group and how the recordings would be used. The participants were asked to sign a consent form acknowledging their participation and to confirm that they were happy to be recorded.

The focus groups were facilitated by the researcher, using a pre-determined set of questions to guide the participant interaction. In relation to the training or lack thereof, participants were asked to discuss the initial experiences of working with Turnitin and Grademark, their relationship with the online marker, and the overall transition into higher education. Each session lasted for around half an hour. After completion of the focus groups, the transcripts were analysed by drawing on a grounded theory approach (see e.g. Charmaz, 2014; Corbin and Strauss, 2014). Transcripts were first openly coded by reading and re-reading the transcripts, and identifying all emerging instances of attitudes, feelings, ideas, thoughts and experiences repeated multiple times. These were constantly compared within and across transcripts. This was done until theoretical saturation had been reached. Memos were written alongside the extraction of codes then, during axial coding, the initial codes were grouped to form thematic relationships. Finally, central and peripheral themes and relationships between themes were established through selective coding.

\section{Results and discussion}

\section{Perceived need for training}

When asked about their experiences of working with online feedback, students who had not taken the learning skills module indicated that 'it was quite hard without having like a proper training' (Participant 3.1). Even though all participants in Group 3 had received some basic form of instruction through their other modules on how to submit work to Turnitin, they felt specific in-depth training was needed. As Participant 3.3 pointed out, 'every tutor at the beginning just talks like really briefly about it, but it's just too fast'. Conversely, those students who had gone through the structured training perceived it as a positive, removing unnecessary stress. They acknowledged that 'Turnitin isn't the easiest 
system to navigate without help and training cleared my confusion' (Survey). Some even felt that the training placed them at an advantage over other students: 'I found that I used it a lot more easily and I understood it better than other students from other courses' (Participant 2.3). Participant 1.1 further pointed out that structured training was, in fact, essential: 'I think if you're just gonna freestyle it, you can't do it'. This idea was similarly expressed by Participant 3.2 from the comparison group, who emphasised that a lack of training places a much greater onus on the students to be proactive in trying to engage with Turnitin: 'We really need to go and search for [support]'.

These views reflect findings from previous work where students expressed a desire for training that supports their engagement with online submission and feedback processes, which they are not averse to in principle (e.g. Hast and Healy, 2016). So despite coming from a generation that is supposed to be comfortable with technology (Manuguerra and Petocz, 2011; Prensky, 2012) it is evident that they still see a need for training to support their engagement with specific digital approaches, especially ones they are unlikely to have experienced outside of higher education. The findings also point to the potential danger of leaving students to their own devices as this may have potential to lead to disengagement with feedback if the cost of effort is too high (cf. McCabe et al., 2011; Parkin et al., 2012), again highlighting the need for structured training to be in place.

\section{Perceived usefulness of training}

From the survey data it is evident that the structured training eased the submission process for students. There were moderate positive correlations between the views on the in-class demonstration and perceived ease of both submitting work, $T=0.48, p<0.001$, and accessing feedback, $T=0.40, p<0.01$. Supporting this, there was a moderate positive correlation between the views on the demonstration and the perceived difficulty of working with Turnitin if training had not been provided, $T=0.42, p<0.01$. However, not only did the training make the submission and access processes easier for students, it also seemed to foster confidence towards future processes. There were moderate positive correlations between the views on the in-class demonstration and confidence both in submitting future work, $T=0.34, p<0.01$, and in accessing future feedback, $T=0.38, p<0.01$. This was also reflected in the open survey responses, as students felt they were, as a result, 'able to submit essays better - easier for the future'. Furthermore, there was a moderate positive correlation between submission ease and confidence in submitting future work, $T=0.45, p$ 
$<0.01$, and a strong positive correlation between feedback access ease and confidence in accessing future feedback, $T=0.57, p<0.001$.

\section{Reducing disengagement and depersonalisation}

A key issue pointed out by students in the comparison focus group was that it would be maybe also helpful if you would have like a tutor to talk about [the feedback]' (Participant 3.2). A similar issue was noted in previous work where students expressed a favouring of face-to-face tutor communication (e.g. Hast and Healy, 2016) - despite not being prohibited from doing so. However, beyond the possible perception that they might not be allowed to speak to a tutor, a further issue contributing to this lack of engagement seems to be marker anonymity: 'I've had my feedback but I don't know who gave the feedback... I would first need to go to everyone' (Participant 3.3). This is an area where structured training is helpful since it supports the clarification of post-feedback engagement. In fact, there was a strong positive correlation between the perceived usefulness of the students' ability to identify the marker and understanding who to speak to about the feedback, $T=$ $0.59, p<0.001$. This ability was seen as important, as exemplified by Participant 2.2's insight: 'Knowing that the feedback was from her... helped me connect with the feedback'.

Conversely, not having this insight reduced the students' perceived efficacy to engage: 'There's so much missing, 'cause you just read it but you can't really interact... you want to see emotions and all that' (Participant 3.4). Critically, the training not only helps students know who marked their work, it allows them to connect with the feedback and the marker on an emotional level, which was seen as missing by Participant 3.4: 'It changes the way you read... if you didn't know, you wouldn't know whose sort of eyes you're reading it through' (Participant 1.2). As a whole, it is evident that structured training is not just seen as necessary to reduce stress; it has the potential to address concerns relating to interpretation (Andrade, 2010; Hattie and Timperley, 2007) and depersonalisation of students in their engagement with online feedback (McCabe et al., 2011; Parkin et al., 2012).

\section{Training and transition into higher education}

A final key area of interest was how structured training might support the overall transition experience into higher education. Where the training had not been experienced, students 
commented on the transition challenges in the particular context of online assessment and feedback: 'I spent quite a lot of time... just to get used to it... it was quite a big transition' (Participant 3.2). Being aware of this perspective should help to understand how appropriate training and support can enhance motivation to engage with feedback and thus reduce potential issues surrounding retention (cf. Gale and Parker, 2014; Kift et al., 2010). This becomes particularly clear when placing this in contrast to the students who went through the structured training, whose views were far more positive in relation to their transition experience. The training 'allowed the transition to be a lot smoother' (Survey), and as a result, Participant 2.4 was able to comment that the training 'has made higher education better'. It is thus evident that appropriate training impacts the overall student transition experience, making it easier and more efficient.

\section{Conclusion and further recommendations}

Despite an ever increasing digitally competent and confident student body, which means higher education institutions must realign and reform their digital approaches to teaching and learning, this student body still requires support to make the transition into higher education - even on a technological level. The data presented here have shown that structured training can support students in an effective manner. It reduces the stress of the overall transition experience, builds confidence in their experiences with submission and feedback access processes, and has the potential to foster their engagement by reducing depersonalisation. However, future research will be needed to examine long-term implications of such training and whether the training can lead to sustained feedback engagement that goes beyond mere access.

\section{References}

Abrahams, D.A. (2010) 'Technology adoption in higher education: a framework for identifying and prioritising issues and barriers to adoption of instructional technology', Journal of Applied Research in Higher Education, 2(2), pp. 34-49 [Online]. Available at: http://doi.org/10.1108/17581184201000012 (Accessed: 22 October 2017). 
Altbach, P.G., Reisberg, L. and Rumbley, L.E. (2009) Trends in global higher education: tracking an Academic revolution. Paris: UNESCO.

Ambler, T., Breyer, Y. and Young, S. (2014) 'Piloting online submission and online assessment with Grademark', in Kennedy-Clark, S., Everett, K. and Wheeler, P. (eds.) Cases on the assessment of scenario and game-based virtual worlds in higher education. Hershey: Information Science Reference, pp. 125-151.

Andrade, H.L. (2010) 'Students as the definitive source of formative assessment', in Andrade, H.L. and Cizek, G.J. (eds.) Handbook of formative assessment. New York: Routledge, pp. 90-105.

Baker, R.K., Thornton, B. and Adams, M. (2008) 'An evaluation of the effectiveness of Turnitin.com as a tool for reducing plagiarism in graduate student term papers', College Teaching Methods \& Styles Journal, 4(9), pp. 1-4 [Online]. Available at: http://dx.doi.org/10.19030/ctms.v4i9.5564 (Accessed: 22 October 2017).

Batane, T. (2010) 'Turning to Turnitin to fight plagiarism among university students', Journal of Educational Technology \& Society, 13(2), pp. 1-12.

Bradwell, P. (2009) The edgeless university: why higher education must embrace technology. London: Demos.

Bridge, P. and Appleyard, R. (2005) 'System failure: a comparison of electronic and paperbased assignment submission, marking, and feedback', British Journal of Educational Technology, 36(4), pp. 669-671 [Online]. Available at: http://dx.doi.org/10.1111/j.1467-8535.2005.00485.x (Accessed: 22 October 2017).

Bridge, P. and Appleyard, R. (2008) 'A comparison of electronic and paper-based assignment submission and feedback', British Journal of Educational Technology, 39(4), pp. 644-650 [Online]. Available at: http://dx.doi.org/10.1111/j.14678535.2007.00753.x (Accessed: 22 October 2017). 
Brown, G.T.L., Peterson, E.R. and Irving, S.E. (2009) 'Beliefs that make a difference: adaptive and maladaptive self-regulation in students' conceptions of assessment', in Mclnerney, D.M., Brown, G.T.L. and Liem, G.A.D. (eds.) Student perspectives on assessment: what students can tell us about assessment for learning. Charlotte: Information Age, pp. 159-186.

Brown, G.T., Peterson, E.R. and Yao, E.S. (2016) 'Student conceptions of feedback: impact on self-regulation, self-efficacy, and academic achievement', British Journal of Educational Psychology, 86(4), pp. 606-629 [Online]. Available at: http://dx.doi.org/10.1111/bjep.12126 (Accessed: 22 October 2017).

Buckley, E. and Cowap, L. (2013) 'An evaluation of the use of Turnitin for electronic submission and marking and as a formative feedback tool from an educator's perspective', British Journal of Educational Technology, 44 4), pp. 562-570 [Online]. Available at: http://dx.doi.org/10.1111/bjet.12054 (Accessed: 22 October 2017).

Charmaz, K. (2014) Constructing grounded theory. London: SAGE.

Corbin, J. and Strauss, A. (2014) Basics of qualitative research: techniques and procedures for developing grounded theory. $4^{\text {th }}$ edn. London: SAGE.

Creswell, J.W. (2015) A concise introduction to mixed methods research. London: SAGE.

Cronbach, L.J. (1951) 'Coefficient alpha and the internal structure of tests', Psychometrika, 16(3), pp. 297-334 [Online]. Available at:

http://dx.doi.org/10.1007\%2FBF02310555?LI=true (Accessed: 22 October 2017).

Gale, T. and Parker, S. (2014) 'Navigating change: a typology of student transition in higher education', Studies in Higher Education, 39(5), pp. 734-753 [Online]. Available at: http://dx.doi.org/10.1080/03075079.2012.721351 (Accessed: 22 October 2017). 
Gosper, M., Malfroy, J. and McKenzie, J. (2013) 'Students' experiences and expectations of technologies: an Australian study designed to inform planning and development decisions', Australasian Journal of Educational Technology, 29(2), pp. 268-282 [Online]. Available at: http://dx.doi.org/10.14742/ajet.127 (Accessed: 22 October 2017).

Grieve, R., Padgett, C.R. and Moffitt, R.L. (2016) 'Assignments 2.0: the role of social presence and computer attitudes in student preferences for online versus offline marking', The Internet and Higher Education, 28, pp. 8-16 [Online]. Available at: http://doi.org/10.1016/j.iheduc.2015.08.002 (Accessed: 22 October 2017).

Hast, M. and Healy, C. (2016) 'Higher education marking in the electronic age: Quantitative and qualitative student insight', Procedia Social and Behavioral Sciences, 228, pp. 11-15 [Online]. Available at: http://dx.doi.org/10.1016/j.sbspro.2016.07.002 (Accessed: 22 October 2017).

Hattie, J. and Timperley, H. (2007) 'The power of feedback', Review of Educational Research, 77(1), pp. 81-112 [Online]. Available at: http://dx.doi.org/10.3102/003465430298487 (Accessed: 22 October 2017).

Heinrich, E., Milne, J. and Granshaw, B. (2012) 'Pathways for improving support for the electronic management and marking of assignments', Australasian Journal of Educational Technology, 28(2), pp. 279-294 [Online]. Available at: http://dx.doi.org/10.14742/ajet.874 (Accessed: 22 October 2017).

Hepplestone, S., Holden, G., Irwin, B., Parkin, H.J. and Thorpe, L. (2011) 'Using technology to encourage student engagement with feedback: a literature review', Research in Learning Technology, 19(2), pp. 117-127 [Online]. Available at: http://dx.doi.org/10.1080/21567069.2011.586677 (Accessed: 22 October 2017).

Kift, S.M., Nelson, K.J. and Clarke, J.A. (2010) 'Transition pedagogy: a third generation approach to FYE - a case study of policy and practice for the higher education sector', The International Journal of the First Year in Higher Education, 1(1), pp. 120 [Online]. Available at: http://dx.doi.org/10.5204/intjfyhe.v1i1.13 (Accessed: 22 October 2017). 
Krueger, R.A. and Casey, M.A. (2014) Focus groups: a practical guide for applied research. London: SAGE.

Lai, K.W. (2011) 'Digital technology and the culture of teaching and learning in higher education', Australasian Journal of Educational Technology, 27(8), pp. 1263-1275 [Online]. Available at: http://dx.doi.org/10.14742/ajet.892 (Accessed: 22 October 2017).

Laurillard, D. (2006) 'E-learning in higher education', in Ashwin, P. (ed.) Changing higher education: the development of learning and teaching. London: Routledge, pp. 7184.

López-Pérez, M.V., Pérez-López, M.C. and Rodríguez-Ariza, L. (2011) ‘Blended learning in higher education: students' perceptions and their relation to outcomes', Computers \& Education, 56(3), pp. 818-826 [Online]. Available at: http://doi.org/10.1016/j.compedu.2010.10.023 (Accessed: 22 October 2017).

López-Pérez, M.V., Pérez-López, M.C., Rodríguez-Ariza, L. and Argente-Linares, E. (2013) 'The influence of the use of technology on student outcomes in a blended learning context', Educational Technology Research and Development, 61(4), pp. 625-638 [Online]. Available at: http://dx.doi.org/10.1007/s11423-013-9303-8 (Accessed: 22 October 2017).

Manuguerra, M. and Petocz, P. (2011) 'Promoting student engagement by integrating new technology into tertiary education: the role of the iPad', Asian Social Science, 7(11), pp. 61-65 [Online]. Available at: http://dx.doi.org/10.5539/ass.v7n11p61 (Accessed: 22 October 2017).

McCabe, J., Doerflinger, A. and Fox, R. (2011) 'Student and faculty perceptions of efeedback', Teaching of Psychology, 38(3), pp. 173-179 [Online]. Available at: http://dx.doi.org/10.1177/0098628311411794 (Accessed: 22 October 2017).

Newman, F. and Scurry, J.E. (2015) 'Higher education and the digital rapids', International Higher Education, 26, pp. 13-14. 
Parkin, H.J., Hepplestone, S., Holden, G., Irwin, B. and Thorpe, L. (2012) 'A role for technology in enhancing students' engagement with feedback', Assessment \& Evaluation in Higher Education, 37(8), pp. 963-973 [Online]. Available at: http://dx.doi.org/10.1080/02602938.2011.592934 (Accessed: 22 October 2017).

Pellegrino, J.W. and Quellmalz, E.S. (2010) 'Perspectives on the integration of technology and assessment', Journal of Research on Technology in Education, 43(2), pp. 119134 [Online]. Available at: http://dx.doi.org/10.1080/15391523.2010.10782565 (Accessed: 22 October 2017).

Prensky, M. (2012) From digital natives to digital wisdom. Thousand Oaks: Corwin.

Säljö, R. (2010) 'Digital tools and challenges to institutional traditions of learning: technologies, social memory and the performative nature of learning', Journal of Computer Assisted Learning, 26, pp. 53-64 [Online]. Available at: https://ai2-s2pdfs.s3.amazonaws.com/60dd/89d8a8298d273858a22bedb0f18fbce743b7.pdf (Accessed: 27 October 2017).

Sarkar, S. (2012) 'The role of information and communication technology (ICT) in higher education for the 21st century', The Science Probe, 1(1), pp. 30-41.

Selwyn, N. (2016) 'Digital downsides: exploring university students' negative engagements with digital technology', Teaching in Higher Education, 21(8), pp. 1006-1021 [Online]. Available at: http://dx.doi.org/10.1080/13562517.2016.1213229 (Accessed: 22 October 2017).

Shaw, S. (2008) 'Essay marking on-screen: implications for assessment validity', ELearning and Digital Media, 5(3), pp. 256-274 [Online]. Available at: http://doi.org/10.2304/elea.2008.5.3.256 (Accessed: 22 October 2017).

Timmis, S., Broadfoot, P., Sutherland, R. and Oldfield, A. (2016) 'Rethinking assessment in a digital age: opportunities, challenges and risks', British Educational Research Journal, 42(3), pp. 454-476 [Online]. Available at: http://dx.doi.org/10.1002/berj.3215 (Accessed: 22 October 2017). 
Turney, C.S.M., Robinson, D., Lee, M. and Soutar, A. (2009) 'Using technology to direct learning in higher education: the way forward?', Active Learning in Higher Education, 10(1), pp. 71-83 [Online]. Available at: http://dx.doi.org/10.1177/1469787408100196 (Accessed: 22 October 2017).

Universities and Colleges Admissions Service (UCAS) (2017) Mature students' guide. Available at: https://www.ucas.com/file/35436/download?token=2Q6wiw-L (Accessed: 21 April 2017).

Walker, R., Voce, J. and Ahmed, J. (2012) 2012 Survey of technology enhanced learning for higher education in the UK. Oxford: UCISA.

\section{Author details}

Michael Hast is Senior Lecturer in Psychology of Education at St Mary's University, Twickenham. His primary research interests lie in early cognitive development and the resulting implications for educational practice. However, he is also interested in how higher education experiences can be improved for students, particularly in the context of engagement with feedback. 